\title{
Efeito de monoterpenos naturais no crescimento micelial e germinação de conídios de Corynespora cassiicola
}

\author{
Natural monoterpenes effect on the mycelial growth and \\ conidial germination of Corynespora cassiicola
}

Adriano Lopes Romero ${ }^{*}$, Ricardo Ribeiro de Oliveira², Rafaelle Bonzanini Romero'

Alessandra Lescano de Almeida², Sergio Paulo Severo de Souza Diniz², João Batista Vida²

RESUMO: Os monoterpenos possuem ampla diversidade estrutural e apresentam atividade inibitória contra uma grande gama de bactérias e fungos. Neste contexto, o presente trabalho teve como objetivo avaliar o efeito fungitóxico de sete monoterpenos naturais $\{$ timol (1), carvacrol (2), p-cimeno (3), D-limoneno (4), (-)-mentona (5), (-)-mentol (6) e (+)-mentol (7) \} sobre o crescimento micelial e germinação de conídios de Corynespora cassiicola. A partir da análise das estruturas moleculares dos monoterpenos 1-7 e seus efeitos nos testes avaliados, observou-se a seguinte sequência de atividade: fenóis $>$ alcoóis $>$ cetonas $>$ hidrocarbonetos. Entre os monoterpenos avaliados, o timol (1), carvacrol (2), (-)-mentol (6) e (+)-mentol (7) foram eficientes no controle in vitro de $C$. cassiicola, contudo estudos complementares a campo são necessários para avaliar o potencial de uso desses compostos.

PALAVRAS-CHAVE: Produtos naturais, atividade antifúngica, timol, carvacrol.
ABSTRACT: Monoterpenes have ample structural diversity and present inhibitory activity against a wide range of bacteria and fungi. In this context, the present work aimed to evaluate the fungitoxic effect of seven natural monoterpenes: \{thymol (1), carvacrol (2), p-cymene (3), D-limonene (4), (-)-menthone (5), (-)-menthol (6), and (+)-menthol (7)\} on the mycelial growth and conidial germination of Corynespora cassiicola. Based on the analyses of the molecular structures of monoterpenes 1-7 and their effect in the evaluated tests, the following sequence of activity was observed: phenols $>$ alcohol $>$ ketones $>$ hydrocarbons. Among the monoterpenes evaluated, thymol (1), carvacrol (2), (-)-menthol (6), and $(+)$-menthol (7) were efficient in the in vitro control of C. cassiicola; however, complementary field studies are necessary to evaluate the potential application of these composites.

KEYWORDS: Natural products, antifungal activity, thymol, carvacrol.

\section{Introdução}

O desenvolvimento de métodos de controle de pragas, desde a origem da agricultura, tem sido um desafio para o homem e, dentro desta perspectiva, o principal método utilizado são os compostos químicos sintéticos. Problemas de poluição do meio ambiente e efeitos tóxicos de produtos químicos sintéticos aos organismos não alvos estimularam as pesquisas em torno do potencial de pesticidas de origem vegetal (AMADIOHA, 2000). Desta forma, vários óleos essenciais têm sido pesquisados como uma alternativa no controle fitossanitário em sistemas de cultivos, em substituição aos pesticidas sintéticos (DINIZ et al., 2009). Esses produtos naturais têm sido amplamente estudados 
por possuírem alta atividade antimicrobiana, baixa toxidade ao homem, serem de fácil degradação e por apresentarem pouco impacto ao meio ambiente (MARQUES; MONTEIRO; PEREIRA, 2004). Entre os constituintes dos óleos essenciais, os monoterpenos são reportados por suas atividades inibitórias contra várias bactérias e fungos. O timol (1) e o carvacrol (2), por exemplo, são dois fenóis monoterpênicos que apresentam atividade inibitória contra uma grande gama de bactérias (HAO; BRACKET; DOYLE, 1998; ULTEE; GORRIS; SMID, 1998) e fungos (CHAO; YOUNG, 2000; VÁZQUEZ et al., 2001).

Corynespora cassiicola, agente causal da mancha alvo ou mancha de corinespora, encontra-se associado a mais de 70 hospedeiras (SILVA et al., 1995), causando danos em algumas de expressão agronômica, como tomate (LEROY; LOURD, 1989; SIVIERO; NODA; ASSIS, 1995), soja (YORINORI; HOMECHIN, 1977), pepino (VERZIGNASSI; VIDA; TESSMAM, 2003; VIDA et al., 2001), seringueira (GASPAROTTO; FERREIRA; JUNQUEIRA, 1988), mamoeiro (DUARTE; ASANO; ALBUQUERQUE, 1983), entre outras. Em pepino 'tipo japonês', a mancha alvo tem se destacado como uma das principais enfermidades nos períodos quentes do ano, causando danos de até 60\% (VERZIGNASSI; VIDA; TESSMAM, 2003; VIDA et al., 2001). Fato semelhante tem ocorrido na cultura do tomate na região norte do Brasil, onde danos de até $100 \%$ à cultura são relatados (LEROY; LOURD, 1989). Ambos os autores, Verzignassi, Vida e Tessmam (2003) e Leroy e Lourd (1989), ressaltam a baixa eficiência dos fungicidas empregados para o controle da doença no campo.

A baixa eficiência no controle da mancha alvo pode estar relacionada com a resistência do patógeno a determinados grupos químicos tradicionalmente empregados para o controle a campo. Date et al. (2004) e Hasama, Morita e Kato (2001) identificaram a existência de biótipos de $C$. cassiicola resistentes a fungicidas do grupo dos Benzimidazois (Tiofanato-metílico). Date et al. (2004) ainda relatam que, dos 193 isolados avaliados, um foi resistente a fungicidas do grupo das Estrubilurinas (azoxistrobina).

Assim, além dos problemas relacionados à poluição e toxicidade dos produtos químicos sintéticos, a baixa eficiência de alguns fungicidas no controle de $C$. cassiicola ressalta a necessidade de se encontrar novos compostos que possam ser utilizados no manejo dessa doença a campo. Neste contexto, o presente trabalho teve como objetivo avaliar o efeito de uma série de monoterpenos naturais na germinação de conídios e crescimento micelial de $C$. cassiicola isolado de tomateiro.

\section{Material e Métodos}

\section{Obtenção dos monoterpenos naturais}

Neste trabalho, foram utilizados os seguintes monoterpenos: timol (1), carvacrol (2), p-cimeno (3), D-limoneno (4), (-)-mentona (5), (-)-mentol (6) e (+)-mentol (7). Estes monoterpenos foram adquiridos da empresa Sigma-Aldrich ou isolados a partir de óleos essenciais, utilizando cromatografia em coluna de sílica gel.

\section{Determinação da composição química}

A identificação e a pureza dos monoterpenos foram determinadas por Cromatografia Gasosa acoplada a Espectrometria de Massas (CG-EM) e por Ressonância Magnética Nuclear (RMN de $\left.{ }^{1} \mathrm{H},{ }^{13} \mathrm{C} / \mathrm{DEPT}\right)$.

\section{Obtenção e multiplicação do isolado de Corynespora cassiicola}

O isolado de $C$. cassiicola foi obtido de plantas de tomateiro cv. Santa Clara com sintomas típicos de mancha alvo. O isolamento em cultura pura foi feito em meio de cultivo BDA (batata-dextrose-ágar), que foram utilizadas para a obtenção das culturas monospóricas. Estas culturas foram mantidas em tubos de ensaio com meio BDA à temperatura de $8 \pm 2{ }^{\circ} \mathrm{C}$ para o armazenamento. Para a multiplicação, fragmentos de micélio da cultura monospórica foram transferidos para placas de Petri contendo BDA, e estas foram mantidas em câmara climatizada do tipo 'BOD', a $25 \pm 2{ }^{\circ} \mathrm{C}$, sob luz fluorescente contínua, por 7 dias.

\section{Atividade antifúngica}

Efeito de monoterpenos no crescimento micelial: O meio de cultivo BDA foi preparado conforme a rotina, em erlenmeyers com a capacidade de 1,0 litro. Contudo, momentos antes de serem vertidos em placas de Petri, quando a temperatura encontrava-se em torno de $40{ }^{\circ} \mathrm{C}$, foram adicionadas aos recipientes soluções contendo os monoterpenos de interesse, previamente preparadas. Estes foram agitados suavemente para que fossem homogeneizados, de modo que, no final, fossem obtidas placas de Petri contendo o meio com as diferentes concentrações de cada monoterpeno a ser avaliado (250; 500; 1000 e 5000 ppm). Foram utilizadas três placas de Petri $(9,0 \mathrm{~cm}$ $\varnothing)$ por tratamento. Depois da solidificação, discos de micélio de 5,0 mm de diâmetro, e sete dias de idade, foram transferidos para o centro das placas, e estas foram incubadas em câmara climatizada do tipo 'BOD', a $25 \pm 2{ }^{\circ} \mathrm{C}$, sob luz fluorescente contínua. As avaliações do crescimento micelial foram realizadas após oito dias, de maneira qualitativa, adotando-se a seguinte escala: (-) Ausência de crescimento; (+) até $1 \mathrm{~cm}$; (++) 1,1 a $2,5 \mathrm{~cm} ;(+++)>2,6 \mathrm{~cm}$.

Efeito de monoterpenos na germinação de conídios: Placas de Petri, contendo culturas monospóricas de C. cassiicola, com 14 dias de idade, foram utilizadas para a obtenção da suspensão de conídios. Em cada placa, adicionaram-se 8,0 mL de água destilada e esterilizada e, com o auxílio de uma alça de Drigalski, raspou-se a superfície do meio de cultivo para a liberação dos conídios das hifas. O extrato obtido foi filtrado em dupla camada de gaze para a obtenção da suspensão de conídios, a qual foi ajustada para a concentração de $5 \times 10^{4}$ conídios/mL. Para a avaliação da germinação de conídios de $C$. cassiicola mediante a aplicação dos diferentes monoterpenos, foram utilizadas placas de ELISA com 96 "poços" (wells). Cada tratamento foi composto de três repetições, sendo um "poço" considerado uma unidade experimental. Em cada "poço" (well) da placa, foram depositados $100 \mu \mathrm{L}$ da suspensão de conídios e, em seguida, $100 \mu \mathrm{L}$ de solução de cada monoterpeno, de forma que se obtivessem concentrações finais de 250; 500; 
1000; e 5000 ppm. Depois da preparação, as placas foram mantidas a $25^{\circ} \mathrm{C}$ sob iluminação constante durante 48 horas. Para a determinação do número de conídios germinados de cada tratamento e repetição, utilizou-se microscópio óptico. Para tal, as placas de Elisa foram drenadas e, para a visualização ao microscópio, foram invertidas.

\section{Resultados e Discussão}

Os efeitos dos monoterpenos timol (1), carvacrol (2), p-cimeno (3), D-limoneno (4), (-)-mentona (5), (-)-mentol (6) e (+)-mentol (7), Figura 1, sobre o crescimento micelial e germinação de conídios do fitopatógeno $C$. cassiicola são apresentados na Tabela 1. Observou-se que os efeitos dos monoterpenos sobre o crescimento micelial e/ou germinação de conídios do fitopatógeno $C$. cassiicola são dependentes da concentração e da estrutura molecular.

Entre todos os monoterpenos testados, apenas o timol (5) inibiu completamente o crescimento micelial de Corynespora cassiicola, em todas as concentrações avaliadas. Para este monoterpeno, a inibição completa da germinação de conídios ocorreu para as três maiores concentrações $(500 ; 1000$; e $5000 \mathrm{ppm}$ ), sendo observada, para a menor concentração (250 ppm), uma inibição de 82,0\%. Resultado semelhante foi observado para o carvacrol (2), que inibiu completamente tanto o crescimento micelial, quanto a germinação de conídios nas três maiores concentrações avaliadas (500; 1000; e 5000 ppm). Contudo, na menor concentração, observou-se um pequeno crescimento micelial $[(+)$ até $1,0 \mathrm{~cm}]$, e inibição de $40,0 \%$ da germinação de conídios (Tabela 1). Estes resultados sugerem que a posição do grupo $\mathrm{OH}$ no anel aromático influencia muito pouco as atividades avaliadas. Vários óleos essenciais que possuem em sua composição timol (1) e/ou carvacrol (2) apresentam atividade antimicrobiana contra um
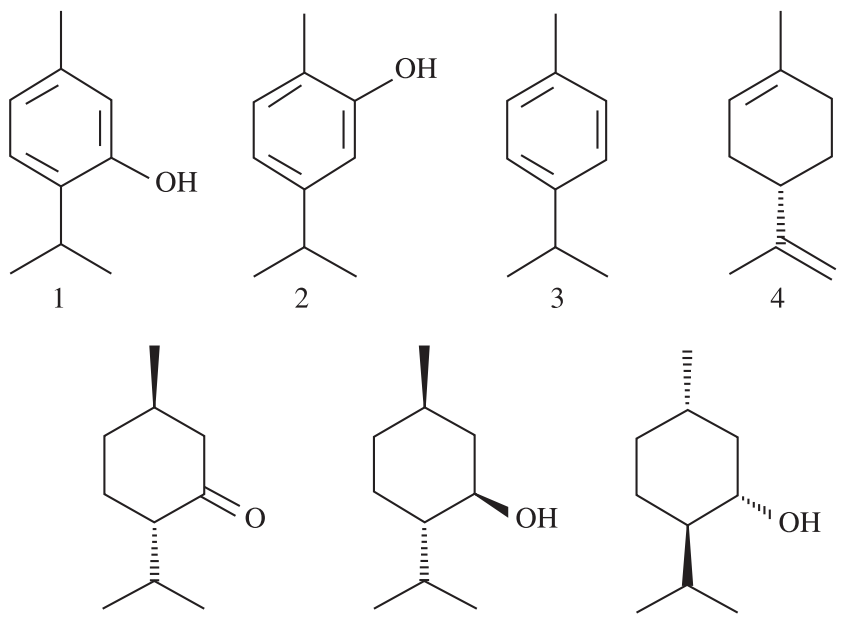

5

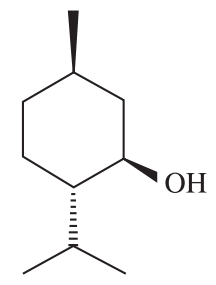

6

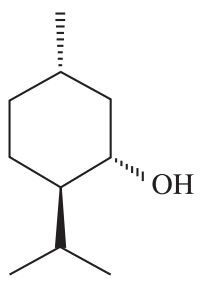

Figura 1. Monoterpenos naturais abundantes em óleos essenciais: timol (1), carvacrol (2), p-cimeno (3), D-limoneno (4), (-)-mentona (5), (-)-mentol (6) e (+)-mentol (7). amplo espectro de micro-organismos. Diniz et al. (2009), por exemplo, observaram que o óleo essencial de tomilho, constituído por timol (50\%), p-cimeno (20\%), carvacrol $(4,5 \%)$ e outros $(25,5 \%)$, apresentaram atividade antifúngica frente aos fitopatógenos Corynespora cassiicola, Erwinia psidii, Sclerotinia minor, Colletotrichum musae, Fusarium moniliforme e Myrothecium verrucaria. Segundo Juven et al. (1994), os fenóis monoterpênicos 1 e 2 ligam-se aos grupos aminas e hidroxilamina de proteínas presentes nas membranas das bactérias, alterando sua permeabilidade e resultando na morte da bactéria. Já a atividade antifúngica pode ser explicada, segundo Zambonelli et al. (1996), pela degeneração das hifas, que causa a liberação do conteúdo celular.

Para os monoterpenos p-cimeno (3) e D-limoneno (4), em todas as concentrações avaliadas, observaram-se crescimento micelial e germinação de conídios (Tabela 1). Estes resultados sugerem que a hidrofobicidade dos monoterpenos não é um requisito para as atividades em questão, uma vez que o p-cimeno (3), precursor dos fenóis monoterpênicos $\mathbf{1}$ e $\mathbf{2}$, apesar de possuir alto coeficiente de partição, influenciou muito pouco o crescimento micelial, assim como a germinação de conídios de C. cassiicola. No entanto, a presença do grupo $\mathrm{OH}$ nos monoterpenos $\mathbf{1}$ e $\mathbf{2}$ é de extrema importância para conferir os efeitos de inibição do crescimento micelial e de germinação de conídios de $C$. cassiicola. Essas características estruturais são concordantes com o mecanismo de ação proposto por Juven et al. (1994) e Zambonelli et al. (1996), no qual a presença de grupos hidrofílicos na estrutura molecular aumenta significativamente a atividade antibacteriana e/ou antifúngica.

Para o monoterpeno (-)-mentona (5), observou-se inibição completa no crescimento micelial e na germinação de conídios na maior concentração utilizada (5000ppm). Na concentração de 1000 ppm, observou-se inibição de 100,0\% do crescimento micelial e de 76,0\% da germinação dos conídios. Para as demais concentrações, 500 e 250 ppm, observaram-se crescimento

Tabela 1. Efeito de alguns monoterpenos na germinação de conídios e crescimento micelial de $C$. cassiicola.

\begin{tabular}{ccccc}
\hline \multirow{2}{*}{ Composto } & \multicolumn{4}{c}{ Concentração (ppm) } \\
\cline { 2 - 5 } & $\mathbf{2 5 0}$ & $\mathbf{5 0 0}$ & $\mathbf{1 0 0 0}$ & $\mathbf{5 0 0 0}$ \\
\hline \multirow{2}{*}{ timol } & $82 \%^{*}$ & $100 \%$ & $100 \%$ & $100 \%$ \\
& $(-)^{* *}$ & $(-)$ & $(-)$ & $(-)$ \\
carvacrol & $40 \%$ & $100 \%$ & $100 \%$ & $100 \%$ \\
& $(+)$ & $(-)$ & $(-)$ & $(-)$ \\
p-cimeno & $0 \%$ & $16 \%$ & $16 \%$ & $16 \%$ \\
& $(+++)$ & $(++)$ & $(+)$ & $(+)$ \\
D-limoneno & $16 \%$ & $16 \%$ & $40 \%$ & $60 \%$ \\
& $(+++)$ & $(+++)$ & $(++)$ & $(+)$ \\
\multirow{3}{*}{$(-)$-mentona } & $6 \%$ & $24 \%$ & $76 \%$ & $100 \%$ \\
& $(+++)$ & $(++)$ & $(-)$ & $(-)$ \\
(-)-mentol & $30 \%$ & $42 \%$ & $100 \%$ & $100 \%$ \\
& $(++)$ & $(-)$ & $(-)$ & $(-)$ \\
\multirow{2}{*}{ (+)-mentol } & $30 \%$ & $56 \%$ & $100 \%$ & $100 \%$ \\
& $(+)$ & $(-)$ & $(-)$ & $(-)$ \\
\hline
\end{tabular}

*Porcentagem de conídios não germinados, $* *$ Crescimento micelial: +++ vigoroso, ++ moderado, + leve, - ausente. 
micelial de "+++" e "++" e inibição da germinação de conídios de 6,0\% e 24,0\%, respectivamente (Tabela 1). Estes resultados sugerem, assim como na discussão anterior, que a presença de um grupo hidrofílico nos monoterpenos aumenta a atividade frente ao C. cassicola. Uma possível explicação para esta observação é a menor habilidade de formar ligações de hidrogênio do monoterpeno 5 em relação os fenóis monoterpênicos 1 e 2.

Os monoterpenos enantioméricos (-)-mentol (6) e (+)-mentol (7) comportaram-se de forma semelhante nos testes avaliados. Para as concentrações de 5000 e 1000 ppm, observou-se completa inibição tanto do crescimento micelial, quanto da germinação de conídios. Para a concentração de 500 ppm, observaram-se inibição completa do crescimento micelial e inibição da germinação de conídios de $42,0 \%$ e $56,0 \%$, respectivamente para o (-)-mentol (6) e o (+)-mentol (7). Na menor concentração (250 ppm), constataram-se um crescimento micelial de "++" e "+", respectivamente para o (-)-mentol (6) e o (+)-mentol (7), e inibição da germinação de conídios de 30,0\% para ambos (Tabela 1). Estes resultados sugerem que: i) monoterpenos enantioméricos não apresentam diferenças significativas frente ao fitopatógeno C. cassicola; ii) fenóis monoterpênicos são mais ativos frente ao fitopatógeno C. cassicola do que os alcoóis monoterpênicos.

A partir da análise das estruturas moleculares dos monoterpenos 1-7 e seus efeitos nos testes avaliados, observou-se a seguinte sequência de atividade: fenóis > alcoóis $>$ cetonas $>$ hidrocarbonetos. Estes resultados são semelhantes aos apresentados por Kurita e Koike (1983), que reportaram que a atividade antifúngica de óleos essenciais frente ao Fusarium verticillioides segue a seguinte sequência de atividade: fenóis $>$ alcoóis $>$ aldeídos $>$ cetonas $>$ hidrocarbonetos .

\section{Conclusão}

Os resultados obtidos in vitro sugerem a potencialidade de aplicação dos monoterpenos timol, carvacrol e mentol para o controle de doenças ocasionadas pelo fitopatógeno Corynespora cassiicola. No entanto, estudos futuros desenvolvidos a campo são requeridos para avaliar a fungitoxicidade e viabilidade destes monoterpenos.

\section{Agradecimentos}

Ao $\mathrm{CNPq}$ (Conselho Nacional de Desenvolvimento Científico e Tecnológico)/MAPA (Ministério da Agricultura, Pecuária e Abastecimento).

\section{Referências}

AMADIOHA, A. C. Controlling rice blast in vitro and in vivo with extracts of Azadirachia indica. Crop Protection, Guildford, v. 19, p. 287-290, 2000. http://dx.doi.org/10.1016/S02612194(99)00080-0
CHAO, S. C.; YOUNG, D. G. Screening for inhibitory activity of essential oils on selected bacteria, fungi and viruses. Journal of Essential Oil Research, Carol Stream, v. 12, n. 5, p. 639-649, 2000. http://dx.doi.org/10.1080/10412905.2000.9712177

DATE, H. et al. Sensitivity of Corynespora cassicola, causal agent of Corynespora leaf spot of cucumber, to thiophanatemethyl, diethofencarb and azoxystrobin. Japanese Journal of Phytopathology, v. 70, n. 1, p. 10-13, 2004. http://dx.doi. org/10.3186/jjphytopath.70.10

DINIZ, S. P. S. S. et al. Atividade do óleo Essencial de Tomilho (Thymus vulgaris L. ) contra Fungos Fitopatogênicos. UNOPAR Científica, Ciências Biológicas e da Saúde, Londrina, v. 11, n. 4 , p. $15-18,2009$

DUARTE, M. L. R.; ASANO, S.; ALBUQUERQUE, F. C. Estudos comparativos das características morfológicas e fisiológicas de dois isolamentos de Corynespora cassiicola. Fitopatologia Brasileira, Brasilia, v. 8, n. 2, p. 205-214, 1983.

GASPAROTTO, L.; FERREIRA, E. A.; JUNQUEIRA, N. T. V. Mancha de Corynespora cassiicola em folhas de seringueira (Hevea brasiliensis) no Brasil. Fitopatologia Brasileira, Brasilia, v. 13, n. 3, p. 278-280, 1988.

HAO, Y.Y.; BRACKET, R. E.; DOYLE, M. P. Efficacy of plant extracts in inhibiting Aeromonas hydrophila and Lysteria monocytogenes in refrigerated cooked poultry. Food Microbiology, London, v. 15, n. 4, p. 367-378, 1998. http://dx.doi.org/10.1006/fmic.1997.0193

HASAMA, W.; MORITA, S.; KATO, T. Control of Corynespora Target Leaf Spot of Cucumber by Use of Negatively-Correlated Cross Resistance between Benzimidazole Fungicides and Diethofencarb. Annals of the Phytopathological Society of Japan, v. 57, n. 3, p. 319-325, 2001. http://dx.doi.org/10.3186/ jjphytopath.57.319

JUVEN, B. J. et al. Factors that interact with the antibacterial action of thyme essential oil and its active constituents. Journal of Applied Bacteriology, Oxford, v. 76, n. 6, p. 626-631, 1994. PMid:8027009. http://dx.doi.org/10.1111/j.1365-2672.1994.tb01661.x

KURITA, N.; KOIKE, S. Synergistic antimicrobial effect of ethanol, sodium chloride, acetic acid and essential oils components Agricultural and Biological Chemistry, Tokyo, v. 47, n. 1, p. 67-75, 1983. http://dx.doi.org/10.1271/bbb1961.47.67

LEROY, M.; LOURD, M. Doença foliar do tomateiro causada por Corynespora cassiicola em Manaus. Fitopatologia Brasileira, Brasilia, v. 14, n. 1, p. 32-36, 1989.

MARQUES, R. P.; MONTEIRO, A. C.; PEREIRA, G. T. Crescimento, esporulação e viabilidade de fungos entomopatogênicos em meios contendo diferentes concentrações do óleo de nim (Azadirachta indica). Ciência Rural, Santa Maria, v. 34, n. 6, p. 1675-1680, 2004

SILVA, W. P. K. et al. RFLP and RAPD analyses in the identification and differentiation of isolates of the leaf spot fungus Corynespora cassiicola. Australian Journal of Botany, Melbourne, v. 43, n. 3 , p. 609-618, 1995. http://dx.doi.org/10.1071/BT9950609

SIVIERO, A.; NODA, H.; ASSIS, L. A. G. Progresso da mancha alvo do tomateiro. Fitopatologia Brasileira, Brasilia, v. 20, p. 281, 1995. Suplemento.

ULTEE, A.; GORRIS, L. G. M.; SMID, E. J. Bactericidal activity of carvacrol towards the food-borne pathogen Bacillus cereus. Journal of Applied Microbiology, Oxford, v. 85, n. 2, p. 211-218, 1998. PMid:9750293. http://dx.doi.org/10.1046/j.13652672.1998.00467.x 
VÁZQUEZ, B. L. et al. Inhibitory effects of eugenol and thymol on Penicillium citrinum strains in culture media and cheese. International Journal of Food Microbiology, Amsterdam, v. 67 , n. 1-2, p. 157-163, 2001. http://dx.doi.org/10.1016/S01681605(01)00429-9

VERZIGNASSI, J. R.; VIDA, J. B.; TESSMAM, D. J. Corynespora cassiicola causando epidemias de manchas foliares em pepino "japonês" sob estufa no Norte do Paraná. Fitopatologia Brasileira, Brasilia, v. 28, n. 5, p. 570, 2003. http://dx.doi.org/10.1590/ S0100-41582003000500023
VIDA, J. B. et al. Manejo de doenças me cultivos protegidos. In: ZAMBOLIM, L. (Ed.). Manejo integrado, fitossanidade, cultivo protegido, pivô central e plantio direto. Viçosa: Suprema Gráfica e Editora Ltda., 2001. p. 53-118.

YORINORI, J. T.; HOMECHIN, M. Doenças de soja identificadas no Estado do Paraná no período de 1971 a 1976. Fitopatologia Brasileira, Brasilia, v. 2, n. 1, p. 108, 1977.

ZAMBONELLI, A. et al. Effects of essential oils on phytopathogenic fungi in vitro. Journal of Phytopathology, Berlin, v. 144, n. 9-10, p. 491-494, 1996. http://dx.doi.org/10.1111/j.1439-0434.1996.tb00330.x

Recebido: 02/09/201 Aprovado: 28/12/2012 